\title{
Plant Sterols/Stanols: Do they have a Role in Current Cardiovascular Disease Prevention?
}

\author{
Theodosios D. Filippatos and Moses S. Elisaf
}

\author{
Department of Internal Medicine, School of Medicine, University of loannina, Ioannina, Greece
}

\begin{abstract}
Plant sterols/stanols inhibit cholesterol absorption in the gastrointestinal tract. The daily consumption of 2 $\mathrm{g} /$ day of plant sterols/stanols decreases low-density lipoprotein cholesterol (LDL-C) levels by approximately $10 \%$. Plant sterols/stanols also reduce LDL-C levels when co-administered with statins, a fact useful for patients intolerable to highdose statins. However, no randomized, controlled clinical trials have examined the clinical benefit of daily consumption of plant sterols/stanols. Furthermore, concerns regarding a possible atherogenic effect of plant sterols have been expressed. The use of plant sterols/stanols-enriched foods is a useful adjunct for hypercholesterolemic patients to achieve their LDL-C target, but we need more data to establish if this hypolipidemic effect results to reduced cardiovascular risk.
\end{abstract}

Keywords: Plant sterols, plant stanols, low-density lipoprotein cholesterol, triglycerides, high-density lipoprotein cholesterol, atherosclerosis, cardiovascular disease.

Hyperlipidemia is a major risk factor for cardiovascular diseases [1]. Current guidelines for the prevention of cardiovascular disease propose, as an adjunct to drug treatment, diet and lifestyle changes in order subjects with elevated low-density lipoprotein cholesterol (LDL-C) levels to reduce their cardiovascular risk. Moreover, they encourage the consumption of specifically targeted 'healthy' functional foods and/or dietary supplements, such as margarine, milk, yoghurt, and cereals enriched with plant sterols/stanols [2].

Plant sterols/stanols inhibit cholesterol absorption in the gastrointestinal tract. During the digestive process, dietary cholesterol is incorporated into mixed micelles, which are absorbed into enterocytes through the Niemann-Pick C1-Like 1 transporter (NPC1L1). Dietary plant sterols/stanols competitively displace cholesterol from mixed micelles leading to inhibition of cholesterol absorption and increase of its excretion in feces [3].

Several trials have shown that the consumption of plant sterols/stanols reduces total cholesterol and LDLC serum concentration. A meta-analysis of 41 randomized controlled trials showed that $2 \mathrm{~g} /$ day plant sterols/stanols from various fatty foods decreased LDLC levels by $10 \%$ [4]. Other meta-analyses have also shown that the consumption of foods enriched in plant sterols/stanols results in a reduction in LDL-C levels of 10-14 mg/dl [5, 6]. Interestingly, intakes of plant stanols in excess of the recommended $2 \mathrm{~g} /$ day dose result

*Address correspondence to this author at the Department of Internal Medicine, School of Medicine, University of loannina, 45110 loannina, Greece; Tel: +30 26510 07509; Fax: +30 26510 07016; E-mail: egepi@cc.uoi.gr in a greater reduction in LDL-C levels compared with maximal doses of plant sterols [7].

Importantly, the consumption of plant sterols/stanols leads also to a further reduction in LDL-C levels when co-administered with statins [8]. A meta-analysis showed that the combination of plant sterols/stanols with a statin led to a further reduction in LDL-C levels by $13 \mathrm{mg} / \mathrm{dl}$ compared with statin monotherapy [9]. Indeed, the addition of plant sterols/stanols to statin treatment leads to at least similar reductions in LDL-C with those observed after doubling the dose of statins. In this context, plant sterols/stanols could be used in cases that high doses of statins are not tolerable.

Most intervention studies with plant sterols/stanols have short duration. However, there is evidence that the LDL-C lowering effect of plant sterols/stanols persists in the long-term. For, example, the Dutch Doetinchem cohort showed that after a 5-year follow-up period patients on statin treatment who consumed margarine enriched in plant sterols/stanols experienced a greater reduction in total cholesterol and non-highdensity lipoprotein cholesterol $(-25 \%$ and $-32 \%$, respectively) levels compared with statin monotherapy $(-21 \%$ and $-27 \%$, respectively) [10].

Plant sterols/stanols also improve other atherosclerosis-related variables. Similarly to LDL-C reduction, the consumption of plant sterols/stanols usually reduces apolipoprotein B levels [11]. A study showed that the consumption of $4 \mathrm{~g} /$ day plant sterols significantly reduced the small dense LDL particles, which are considered the most atherogenic LDL particles, in subjects with metabolic syndrome $[12,13]$. A parallel reduction in oxidized LDL concentration has 
been observed with the improvement of LDL-C levels [14]. Furthermore, increases of $5 \%$ to $11 \%$ in HDL-C levels have been reported in some studies, along with a reduction in LDL-C/HDL-C ratio, effects that may improve cardiovascular risk $[11,15]$. Interestingly, the observed changes in HDL-C levels are possibly attributed to an increase in the large HDL-2 subclasses [16]. A decrease in triglyceride levels has been observed with plant sterols/stanols supplementation, especially in subjects with high baseline TG levels [2, $11]$.

However, there are concerns regarding the consumption of high amounts of plant sterols/stanols. Plant sterols/stanols are incorporated into cellular membranes and deleterious effects have been described in red blood cell membranes of stroke-prone spontaneously hypertensive rats [17]. On the other hand, studies in humans and other animal models did not show an increase in red cell fragility with the consumption of plant sterols/stanols [18, 19]. It has been reported, although not consistently, that a slight reduction in the plasma concentration of some carotenoids, lycopene and fat-soluble vitamins is a possible consequence of the consumption of high amounts of plant sterols/stanols [4]. Moreover, plant sterols/stanols supplementation is contraindicated in individuals with phytosterolemia, who are characterized by tendon xanthomas and premature atherosclerosis [20]. Based on the atherogenic effects of very high concentrations of plant sterols in phytosterolemia, many scientists have questioned the use of plant sterol-enriched foods, which result in a small increase in plant sterol serum concentration [21]. Furthermore, more research is needed to establish if there is any difference in terms of cardiovascular risk reduction between plant sterols and stanols.

The beneficial effect on LDL-C concentration makes plant sterols/stanols a useful adjunct in the treatment of hypercholesterolemic patients. The additive effect on LDL-C concentration may also lead to a reduction in cardiovascular events, if we extrapolate the results of the recently announced IMPROVE-IT trial that showed a reduction in cardiovascular risk with the addition to statin treatment of a drug that inhibits cholesterol absorption (ezetimibe) [22]. However, no evidence from large randomized trials exists regarding the effects of plant sterols/stanols-enriched foods on hard cardiovascular endpoints. The absence of data from large trials and the concerns that have been expressed regarding possible atherogenic effects of increased serum concentration of plant sterols should be taken into account by clinicians who treat hypercholesterolemic patients.

\section{REFERENCES}

[1] European Association for Cardiovascular Prevention and Rehabilitation, Reiner Z, et al. ESC/EAS Guidelines for the management of dyslipidaemias: the Task Force for the management of dyslipidaemias of the European Society of Cardiology (ESC) and the European Atherosclerosis Society (EAS). Eur Heart J 2011; 32: 1769-818. http://dx.doi.org/10.1093/eurhearti/ehr158

[2] Gylling $\mathrm{H}$, Plat J, Turley $\mathrm{S}$, et al. Plant sterols and plant stanols in the management of dyslipidaemia and prevention of cardiovascular disease. Atherosclerosis 2014 ; 232: 34660.

http://dx.doi.org/10.1016/j.atherosclerosis.2013.11.043

[3] Sanclemente T, Marques-Lopes I, Puzo J, et al. Role of naturally-occurring plant sterols on intestinal cholesterol absorption and plasmatic levels. J Physiol Biochem 2009; 65: 87-98.

http://dx.doi.org/10.1007/BF03165972

[4] Katan MB, Grundy SM, Jones P, et al. Efficacy and safety of plant stanols and sterols in the management of blood cholesterol levels. Mayo Clin Proc 2003; 78: 965-78. http://dx.doi.org/10.1016/S0025-6196(11)63144-3

[5] Abumweis SS, Barake R, Jones PJ. Plant sterols/stanols as cholesterol lowering agents: A meta-analysis of randomized controlled trials. Food Nutr Res 2008; 52.

http://dx.doi.org/10.3402/fnr.v52i0.1811

[6] Demonty I, Ras RT, van der Knaap HC, et al. Continuous dose-response relationship of the LDL-cholesterol-lowering effect of phytosterol intake. J Nutr 2009; 139: 271-84. http://dx.doi.org/10.3945//jn.108.095125

[7] Musa-Veloso K, Poon TH, Elliot JA, et al. A comparison of the LDL-cholesterol lowering efficacy of plant stanols and plant sterols over a continuous dose range: results of a metaanalysis of randomized, placebo-controlled trials. Prostaglandins Leukot Essent Fatty Acids 2011; 85: 9-28. http://dx.doi.org/10.1016/j.plefa.2011.02.001

[8] Goldberg AC, Ostlund RE, Jr., Bateman JH, et al. Effect of plant stanol tablets on low-density lipoprotein cholesterol lowering in patients on statin drugs. Am J Cardiol 2006; 97: 376-9.

http://dx.doi.org/10.1016/j.amjcard.2005.08.056

[9] Scholle JM, Baker WL, Talati R, et al. The effect of adding plant sterols or stanols to statin therapy in hypercholesterolemic patients: systematic review and metaanalysis. J Am Coll Nutr 2009; 28: 517-24. http://dx.doi.org/10.1080/07315724.2009.10719784

[10] Eussen SR, de Jong N, Rompelberg CJ, et al. Dosedependent cholesterol-lowering effects of phytosterol/phytostanol-enriched margarine in statin users and statin non-users under free-living conditions. Public Health Nutr 2011; 14: 1823-32. http://dx.doi.org/10.1017/S1368980011000164

[11] Derdemezis CS, Filippatos TD, Mikhailidis DP, et al. Review article: effects of plant sterols and stanols beyond lowdensity lipoprotein cholesterol lowering. J Cardiovasc Pharmacol Ther 2010; 15: 120-34. http://dx.doi.org/10.1177/1074248409357921

[12] Sialvera TE, Pounis GD, Koutelidakis AE, et al. Phytosterols supplementation decreases plasma small and dense LDL levels in metabolic syndrome patients on a westernized type diet. Nutr Metab Cardiovasc Dis 2012; 22: 843-8. http://dx.doi.org/10.1016/..numecd.2010.12.004

[13] Gazi I, Tsimihodimos V, Filippatos T, et al. Concentration and relative distribution of low-density lipoprotein subfractions in 
patients with metabolic syndrome defined according to the National Cholesterol Education Program criteria. Metabolism 2006; 55: 885-91.

http://dx.doi.org/10.1016/j.metabol.2006.02.015

[14] Hansel B, Nicolle C, Lalanne F, et al. Effect of low-fat, fermented milk enriched with plant sterols on serum lipid profile and oxidative stress in moderate hypercholesterolemia. Am J Clin Nutr 2007; 86: 790-6.

[15] Filippatos TD, Elisaf MS. High density lipoprotein and cardiovascular diseases. World J Cardiol 2013; 5: 210-4. http://dx.doi.org/10.4330/wic.v5.i7.210

[16] Demonty I, Chan YM, Pelled D, et al. Fish-oil esters of plant sterols improve the lipid profile of dyslipidemic subjects more than do fish-oil or sunflower oil esters of plant sterols. Am J Clin Nutr 2006; 84: 1534-42.

[17] Ratnayake WM, L'Abbe MR, Mueller R, et al. Vegetable oils high in phytosterols make erythrocytes less deformable and shorten the life span of stroke-prone spontaneously hypertensive rats. J Nutr 2000; 130: 1166-78.

[18] Jones PJ, Raeini-Sarjaz M, Jenkins DJ, et al. Effects of a diet high in plant sterols, vegetable proteins, and viscous fibers (dietary portfolio) on circulating sterol levels and red cell fragility in hypercholesterolemic subjects. Lipids 2005; 40: 169-74. http://dx.doi.org/10.1007/s11745-005-1372-6

[19] de Jong A, Plat J, Mensink RP. Plant sterol or stanol consumption does not affect erythrocyte osmotic fragility in patients on statin treatment. Eur J Clin Nutr 2006; 60: 98590.

http://dx.doi.org/10.1038/sj.ejcn.1602409

[20] Escola-Gil JC, Quesada H, Julve J, et al. Sitosterolemia: diagnosis, investigation, and management. Curr Atheroscler Rep 2014; 16: 424.

[21] Fransen HP, de Jong N, Wolfs $M$, et al. Customary use of plant sterol and plant stanol enriched margarine is associated with changes in serum plant sterol and stanol concentrations in humans. J Nutr 2007; 137: 1301-6.

[22] Filippatos TD, Elisaf MS. Are Lower Levels of LDLCholesterol Really Better? Looking at the Results of IMPROVE-IT: Opinions of Three Experts - III. Hellenic J Cardiol 2015; 56: 7-9. 